\title{
Two Types of Epistemic Instrumentalism
}

Charles Côté-Bouchard

Forthcoming in Synthese

Penultimate draft - please cite published version

\section{Introduction}

In the theory of normativity, instrumentalism is an approach that views the norms or the normativity of a domain as essentially involving the instrumental relation between means and ends. Epistemic instrumentalism (EI), then, views the epistemic domain as essentially involving instrumental or means-end norms and normativity. ${ }^{1}$

I do two main things in this paper. In part 1, I argue that there is an under-appreciated distinction between two independent types of EI. These are what I call norm-instrumentalism (norm-EI) and source-instrumentalism (source-EI). In part 2, I argue that this under-appreciated distinction matters for the debate surrounding the plausibility of EI. Specifically, whether we interpret EI as norm-EI or as source-EI matters (i) for the widely discussed universality or categoricity objection to EI, and (ii) for two important motivations for adopting EI, namely naturalism and the practical utility of epistemic norms. I conclude by drawing some lessons for epistemic instrumentalism going forward.

\footnotetext{
${ }^{1}$ Foley (1987), (1993), Giere (1989), Maffie (1990), Laudan, (1990a), (1990b), Kornblith, (1993), Nozick (1993), Quine (1998), Leite (2007), Schroeder (2007), Cowie (2014), Steglich-Petersen (2018), Sharadin (2018). See also Siegel (1996), Kelly (2003), Cuneo (2007), Lockard (2013), and Côté-Bouchard (2015), (2016) for criticisms of EI.
} 


\section{Instrumentalism about epistemic norms, instrumentalism about epistemic normativity}

\subsection{Two kinds of questions about normative epistemology}

Two sorts of questions have been at the center of recent discussions of epistemology as a normative domain. First are questions about the content and structure of epistemic norms. Norms, I will assume, are claims or propositions that specify the conditions under which some behaviour counts as permitted, required, good, and the like. Epistemic norms, then, are claims or propositions that specify the distinctly epistemic conditions under which some relevant behaviours (most centrally, the doxastic attitudes of belief, disbelief, and suspension of judgment) count as permitted, required, good, and the like. ${ }^{2}$

The first kind of questions, then, are about determining how we should behave, epistemically speaking. What is it, in other words, to be epistemically justified, rational, and the like? $?^{3}$ Is it always epistemically impermissible or bad to believe falsehoods? Should we be consequentialists and view epistemic norms as having to do with the promotion of epistemic goods? Or should we be non-consequentialists and view deontic epistemic requirements as prior to epistemic value? I will refer to this first broad category of questions as norm-questions about the epistemic domain.

These, however, need to be distinguished from a second kind of questions about normative epistemology. These are questions about the nature of epistemic normativity, i.e., about the normative or reason-giving authority of epistemic norms. What is the source or grounding explanation of that normativity? In virtue of what do epistemic norms and standards have the authority that they have over agents? Is it because being epistemically rational is in our self-interest? Because it is conducive to human flourishing? Or, is the normative authority of epistemic norms a sui generis or brute fact? What kind of normativity or authority do epistemic norms have, as a result? Is there necessarily a normative reason to conform to epistemic norms or is epistemology more like etiquette, i.e., a domain that lacks necessary reason-giving force? I will refer to this second kind of questions as source-questions about the epistemic domain.

Norm-questions and source-questions are distinct and, to a large extent, independent from each other. While the former are about, roughly, what it is to be epistemically in the clear, source-questions are about why we should even be epistemically in the clear. What reasons do we have, in other words, to conform to epistemic norms and be epistemically rational in the first place? One can very well give an account of what epistemic norms require without telling us why we should follow these norms. Conversely, one can very well offer a grounding explanation

\footnotetext{
${ }^{2}$ For more on this, see Littlejohn \& Turri (2014). I follow the common usage, among contemporary epistemologists, of taking "epistemic" conditions to mean conditions having to do with notions like knowledge, truth, adequation with evidence, and coherence.

${ }^{3}$ I am assuming here that notions like justification and rationality have to do with norms. To be epistemically justified, rational, and the like is to meet some (epistemic) norm(s). Note that I am not thereby committed to what Alston (1988) calls a "deontological" conception of epistemic justification and rationality. I leave open the possibility that epistemic norms are evaluative instead of deontic or prescriptive, i.e., norms specifying conditions under which doxastic attitudes are epistemically good or bad, rather than permitted or obligatory.
} 
of the normativity of epistemic norms while remaining agnostic about the precise content and structure of those norms. ${ }^{4}$

This distinction between norm-questions and source-questions is not unique to the epistemic domain. Consider the moral domain, for instance. On the one hand, we can ask about the content and structure of moral norms. What is it to be morally justified, right, good, and the like? Are moral norms best accounted for by a consequentialist or non-consequentialist framework? On the other hand, we can also ask about the normative authority of these norms. What is the source of moral normativity? In virtue of what do we have normative reasons to conform to moral norms? Is it because it is in our self-interest to be moral? Because it is conducive to human flourishing? Or is the normative authority of morality a brute fact?

As with the epistemic domain, these two sorts of questions are distinct and, to a large extent, independent from each other. While the former asks what it is to be moral, the latter asks why we should even be moral in the first place. One can very well give an account of what moral norms are like without telling us why we should follow these norms. One may, for instance, defend a classical utilitarian approach to moral norms without telling us why we should be moral and maximize happiness in the first place. Conversely, one can very well give us a grounding explanation of the normativity of morality while remaining agnostic about what moral norms are like exactly. One could, for instance, argue that the necessary authority of morality is a brute fact while remaining neutral in the dispute between consequentialists and non-consequentialists.

How does this matter for epistemic instrumentalism (EI)? As pointed out above, EI is, at its most general, the view that the epistemic domain is essentially tied to the instrumental relation between means and ends. As such, instrumentalism can be (and has been) used as an approach to both norm-questions and source-questions. What I would like to show in this first part is that just like norm-questions and source-questions, instrumentalism about norm-questions and instrumentalism about source-questions are distinct and, to a significant extent, independent from each other. They yield an under-appreciated distinction between two types of EI (norm-EI and source-EI) that do not entail one another.

\subsection{Norm-EI and source-EI}

Consider first an instrumentalist approach to norm-questions. What do epistemic norms require, permit or positively evaluate? What is it to be epistemically justified, rational, and the like? Instrumentalists answer as follows: epistemic norms are instrumental or means-end norms. That is, they are a distinctly epistemic subset of norms that require, permit, or positively evaluate taking the means to our ends. What marks those instrumental norms as epistemic (and not, say, prudential or moral) is that the ends in question are distinctly epistemic ends such as believing

\footnotetext{
${ }^{4}$ I return to this point below. This is not to say, of course, that these two kinds of questions are totally independent from each other. It might be that certain views about norm-questions constrain the answer one can give to sourcequestions, and vice-versa. Relatedly, one cannot elucidate the normativity of epistemic norms without making some assumptions about what these norms are like and what they require. This, however, is compatible with what I say in what follows. To anticipate, my point will simply be that one can be an instrumentalist about epistemic norms without being an instrumentalist about epistemic normativity, and vice-versa. Thanks to an anonymous referee for pressing me on this point.
} 
the truth and avoiding false belief. This is often put in terms of epistemic rationality: the requirements of epistemic rationality are an epistemic subset of the requirements of instrumental or means-end rationality. To be epistemically rational, in other words, is essentially to take the means to one's epistemic ends. This yields a first type of EI, which I will refer to as norm-EI:

Norm-EI Epistemic norms require, permit, or positively evaluate taking the means to satisfy one's epistemic ends. To be epistemically rational is for one to take the means to one's epistemic ends. ${ }^{5}$

Now consider source-questions about the epistemic domain. What is the source of the normative authority of epistemic norms? In virtue of what do we have normative reason to conform to epistemic norms and be epistemically rational? As with norm-questions, we can also use an instrumentalist approach to source-questions. This yields a second type of EI, which I will refer to as source-EI:

Source-EI We have normative reason to conform to epistemic norms - or to be epistemically rational - because, and insofar as doing so is a means to the satisfaction of our ends. ${ }^{6}$

Although they both invoke the means-end relation, norm-EI and source-EI are distinct theses. On the one hand, giving an account of what epistemic norms (as norm-EI does) require, permit, or positively evaluate leaves open how to answer source-questions exactly. Saying that epistemic norms are requirements to take the means our epistemic ends does not, by itself, settle the question of why or in virtue of what we should be instrumentally rational and take the means to those epistemic ends. It says what it is to be epistemically rational, but not why we ought to be epistemically rational.

In contrast, source-EI does tell us why we should conform to epistemic norms: we should do so because, and insofar as doing so is a means to the satisfaction of our ends. But just like norm-EI does not settle source-questions, source-EI does not settle norm-questions. Even if the authority of epistemic norms comes from our ends, that alone does not tell us what epistemic norms are like. Specifically, it does not mean that epistemic norms require, permit, or favour taking the means to our epistemic ends.

\footnotetext{
${ }^{5}$ To be clear, norm-EI is not merely a thesis about the linguistic form of epistemic norms. It is rather a substantive thesis about what epistemic norms require, permit, or positively evaluate. It is the idea that having the relevant epistemic ends is part of the conditions under which something can count as epistemically good, required, or permitted for you. Epistemic ends are part of the conditions of applications of epistemic norms, in other words. I return to this point below, in section 2.1.1. Thanks to an anonymous referee for raising this issue.

${ }^{6}$ Note that unlike norm-EI, what makes source-EI an epistemic form of source-instrumentalism is not the epistemic character of the relevant ends. Rather, it counts as epistemic because it is an account of the normativity of epistemic norms and rationality (and not, say, prudential rationality). According to source-EI, the normative authority of epistemic norms comes from any of our ends, including non-epistemic ones. I return to this point in section 2.1.2.
} 


\subsection{The independence of norm-EI and source-EI}

Even though they are distinct, it is natural to think that norm-EI and source-EI go together. If you think that epistemic norms require taking the means to our ends, then don't you think it's because our ends are the source of epistemic normativity? And if you think epistemic normativity comes from ends, then doesn't that mean that epistemic norms are requirements to take the means to our ends? Not necessarily. Not only are norm-EI and source-EI distinct, they are also independent. Although it is obviously possible to accept both, it is also possible to accept one without the other.

Consider an analogy with the divine command theory (DCT) in ethics. DCT can be used as an approach to both moral norms and moral normativity. According to what we might call norm-DCT, moral norms are requirements to do what God commands or wills. To do what is morally right or good, in other words, is to do what God commands. According to what we might call source-DCT, in contrast, we have normative reason to conform to moral norms because, and to the extent that God's commands us to do so. It is in virtue of the fact that God commands us to be moral that we have a reason to be moral.

Importantly, norm-DCT and source-DCT do not necessarily entail each other. On the one hand, we could view moral norms themselves as God's commands (accept norm-DCT), while at the same time viewing the normative authority of those norms as coming from a source other than God. One could claim, for instance, that we have reason to conform to God's commands because it is conducive to human flourishing. Or perhaps it is a brute fact that we always have normative reason to do as God commands. On the other hand, we could view the normativity of moral norms as coming from the fact that God wants us to be moral (accept source-DCT), while at the same time viewing moral norms themselves not as God's commands, but rather as, e.g., the obligation to maximize happiness. On that other possible combination of views, you have reason to be moral (maximize happiness) because and insofar as God commands you to be moral.

The same is true of norm-EI and source-EI. First, you can very well accept norm-EI and reject source-EI. That is, you can claim that epistemic norms are requirements to take the means to one's epistemic ends without claiming that these requirements have authority just in case conforming to them leads to the satisfaction of our ends. You could, for instance, claim that we have reason to take the means to our epistemic ends (conform to epistemic norms as conceived by norm-EI) because it is morally good to do so, because true beliefs are intrinsically good, because God commands it, and so on. Or perhaps it is a brute fact that we have reason to take the means to our epistemic ends. Accepting these views about epistemic normativity would mean rejecting source-EI. On these possible views, although epistemic norms themselves are instrumental norms, our reasons to conform to them do not come from our ends.

Conversely, you can very well accept source-EI and reject norm-EI. Suppose you think we always have normative reason to follow epistemic norms because believing the truth and avoiding error is always a means to at least some of our ends. You can very well hold that view while rejecting the idea that epistemic norms are requirements, permissions, or recommendations 
to take the means to our epistemic ends. You can accept source-EI, in other words, while rejecting the idea that to be epistemically rational is to take the means to our epistemic ends. You could claim, for example, that being epistemically rational is rather a matter of conforming to prima facie epistemic duties such as the duty to avoid false beliefs, follow the evidence, believe the truth, avoid incoherence, and the like, regardless of what epistemic ends you happen to have. Alternatively, you could hold a divine command theory according to which to be epistemically rational is to believe what God wants you to believe. On these possible accounts, epistemic norms are not instrumental norms; they are not requirements to take the means to our epistemic ends. Yet, they are compatible with source-EI. You could very well accept that epistemic norms are the above prima facie duties or commands from God while maintaining that we have reason to follow those imperatives just in case it promotes the satisfaction of our ends. Perhaps you have the end of being recognized as a top scientist and conforming to the above prima facie duties is a means to that end. Or perhaps you have reason to respect God's doxastic commands because you have the end of going to Heaven.

Although EI has received considerable attention in recent years, the distinction between norm-EI and source-EI has been mostly overlooked. Many authors tend to move freely between the two and to use the phrase "epistemic instrumentalism" to denote instrumentalism about both epistemic norms and epistemic normativity. For example, Larry Laudan maintains that "normative rules of epistemology are best construed as hypothetical imperatives, linking means and end" (Laudan 1990a, 46) and that "[e]pistemic rationality, no less than any other sort of rationality, is a matter of integrating ends and means." (Laudan, 1990b, p. 318). But he also thinks his view:

[..] tell[s] us how justification-rules or methodological rules can themselves be justified or warranted. [...] I have claimed that rules are best seen, especially with respect to their justification, as proposed means to the realization of desired ends. To put it crudely, one is justified in following a methodological rule to the extent that one has good reasons to believe that it will promote the ends of inquiry. (Emphasis added, Laudan 1990b, 315316)

While the former passages are best seen as statements of norm-EI, the latter seems to concern source-questions. It seems to be about why we should take the means to our epistemic ends.

Similarly, Thomas Kelly (2003) defines EI as the view that "epistemic rationality is a species of instrumental rationality, viz. instrumental rationality in the service of one's cognitive or epistemic goals." (612) But then, when discussing why EI matters, Kelly writes:

[T] he instrumentalist conception of epistemic rationality seems to promise a way of preserving a full-blooded, cognitivist account of epistemic normativity which is naturalistically unproblematic. After all, many philosophers regard the normativity 
characteristic of the reasons which one has to take the means to one's ends as utterly unproblematic for naturalism. And if in fact the normativity of instrumental reason is naturalistically unproblematic, and epistemic normativity is simply the normativity of instrumental reason, then (presumably) epistemic normativity is itself naturalistically unproblematic. [...]." (Kelly 2003, 616)

While the former passage does not obviously concern source-EI, the latter clearly does. It suggests that $\mathrm{EI}$ is or entails an account of the normativity of epistemic rationality.

Others use the label "epistemic instrumentalism" to denote only one of the two types of EI. Some of the more recent statements of EI are explicitly restricted to source-EI. Christopher Cowie (2014), for instance, writes:

I understand instrumentalism and intrinsicalism as rival views of the explanatory grounds of epistemic normativity. Both views provide an explanation of what it is in virtue of which there is reason to believe in accordance with one's evidence. [...] [W] hat explains why evidence is normative for belief [...] is the role that evidentially-supported belief plays in facilitating the goals that one possesses, or should possess. (Cowie 2014, 4004$4005)^{7}$

Similarly, Nathaniel Sharadin (2018) introduces EI as follows:

Why is there a reason to believe in accord with the evidence? This [...] is a question about the source of normativity of epistemic reasons. [...] [I]nstrumentalism, says that there is a reason to believe in accord with the evidence because doing so is an instrumentally rational way of achieving the ends, goals, or interests one has. (Sharadin $2018,3792)^{8}$

Finally, some instrumentalists like Papineau (1999) are best interpreted as accepting norm-EI, but not source-EI. While he views epistemic norms as requirements to take the means to our end of truth, Papineau (1999) suggests a pluralist answer to source-questions according to

\footnotetext{
${ }^{7}$ Note that Cowie mentions not only the ends that one does have, but also the ends that one should possess as the source of epistemic normativity. Does this mean Cowie is not really a proponent of source-EI? Not necessarily. It depends on the source of the "should" in "should possess". In virtue of what, according to Cowie, should one possess these ends? If it is in virtue of further ends that she does have, then this can reasonably be seen as a form of source-EI. Alternatively, one could perhaps defend a version of source-EI according to which epistemic normativity comes from one's idealized ends (the ends one would have if she were fully informed and rational). In any case, Cowie can at least be interpreted as a proponent of source-EI and I will use this interpretation in what follows. Thanks to an anonymous referee for raising this point.

${ }^{8}$ Other authors who are primarily concerned with EI understood as source-EI include Kornblith (1993), Schroeder (2007), Cuneo (2007), and Côté-Bouchard (2015).
} 
which the normativity of epistemic means-end requirements comes from multiple sources, including moral and prudential value. ${ }^{9}$

There is, then, an under-appreciated distinction between two types of epistemic instrumentalism. One is norm-EI, the view that epistemic norms are instrumental requirements to take the means to one's epistemic ends. The other is source-EI, the view that we have reason to conform to epistemic norms because and insofar as being epistemically rational is a means to our ends. Those two types of EI are not only distinct, but also independent from each other.

\footnotetext{
${ }^{9}$ Note that very few instrumentalists have defended norm-EI while clearly rejecting source-EI. Proponents of normEI tend to either endorse (or assume) source-EI, or to more or less ignore source-questions. This, however, does not undermine the distinction and its significance. First, as I have argued, there is a distinction. One clearly can accept norm-EI without source-EI. Second, as I argue below, some of the most prominent motivations and defences of EI apply to source-EI, but not to norm-EI. So, even if there are not many proponents of norm-EI who reject source-EI, the distinction still matters for those who want to defend norm-EI, whether or not they also accept source-EI.
} 


\section{Consequences for the debate}

The distinction drawn in part 1 has significant consequences for considerations that are commonly invoked for and against EI. In particular, it matters for the widely discussed universality or categoricity objection to EI, for the prominent claim that naturalism is a motivation for adopting EI, and for the idea that the practical utility of epistemic norms is a motivation for adopting EI. I argue that (i) the most prominent strategies in response to the universality objection are only available to source-EI, (ii) naturalism can only serve as a motivation to adopt source-EI, and (iii) the practical utility of epistemic norms cannot serve as a motivation to adopt norm-EI either.

\subsection{Norm-EI, source-EI, and the universality objection}

\subsubsection{The universality objection}

Epistemic instrumentalism is often said to be ruled out by the universality or categoricity of epistemic norms and epistemic rationality. This is the most commonly discussed objection to EI. It features in most, if not all recent publications about epistemic instrumentalism. ${ }^{10}$ One way to put the objection is that the universality of epistemology makes EI vulnerable to counterexamples. If EI is true, then you should do things like follow the evidence and avoid error only if doing so would promote the satisfaction of your ends. Epistemic norms or normativity are thus, in some sense, conditional on your possessing certain ends. But intuitively, epistemic norms can apply or have authority on agents even when they lack the relevant end(s).

This objection has been made forcefully by Kelly (2003) who identifies two kinds of universality counter-examples. First, there are cases of epistemic indifference, in which agents lack the relevant epistemic ends because they are utterly indifferent about the matter at hand. Second, there are also cases of truth-avoidance where agents' lack those ends because they want to avoid knowing the truth about the matter at hand. Here is an example of epistemic indifference ${ }^{11}$ :

Delaware's Beverage Like most people, Nancy has absolutely no desire to know what the official beverage of the state of Delaware is. Unbeknownst to her however, her friend Brett, whom she knows to be extremely reliable, has recently developed a deep obsession for Delaware. One day he comes up to her and says: 'Listen to me, Nancy. I've got to tell you something. I just found out that the state beverage of Delaware is milk! Isn't that amazing?'

As Lockard $(2013,1707)$ puts it, examples like this suggest that indifference about the truth of the matter at hand is epistemically irrelevant. The fact that an agent does not care at all about whether P seems irrelevant to her epistemic reasons to believe or disbelieve P. Even if Nancy

\footnotetext{
${ }^{10}$ See, for instance, Siegel (1996), Kornblith (1993), Papineau (1999), Kelly (2003), Schroeder (2007), Leite (2007), Cuneo (2007), Lockard (2013), Côté-Bouchard (2015), Sharadin (2018), and Steglich-Petersen (2018).

${ }^{11}$ I use the following two examples in Côté-Bouchard (2015). The second example, "Spoiler Alert", is adapted from Kelly $(2003,626)$.
} 
really is indifferent about Delaware's beverage, it is still epistemically rational, justified, and reasonable for her to believe that it is milk. If EI were true, however, her indifference (her lacking the relevant ends) would not be epistemically irrelevant in that way. This is because, according to EI, epistemic norms or epistemic normativity depend on having the relevant ends. So, EI must be mistaken.

Here is an example of truth-avoidance:

Spoiler Alert Max missed the finale of his favorite television series, which aired last night and revealed whether character $X$ ends up dying. Given his passion for the show, Max really wants to avoid learning the answer to that question before he watches the rerun tonight after work. But to his dismay, one of his colleagues comes up to him in the morning shouting: 'I knew it! I told you character X would die!'

Examples like this suggest that the end of truth-avoidance is also epistemically irrelevant. The fact that an agent wants to avoid learning the truth about $\mathrm{P}$ is irrelevant to what she epistemic should believe. Even if Max really wants to avoid learning the truth about the show's ending, it is still epistemically rational, justified, and reasonable for him to believe that $\mathrm{X}$ dies. He still has epistemic reasons to believe that $\mathrm{X}$ dies. If EI were true, however, truth-avoidance would not be epistemically irrelevant since, according to EI, epistemic norms or epistemic normativity depend on having the relevant ends.

The universality objection can be construed both as a challenge to norm-EI and to sourceEI. That is, each of norm-EI and source-EI, face their own version of the universality objection. To see this, note first that both of them see their subject-matter as dependent or conditional on possessing certain ends. While source-EI sees the authority of epistemic norms as depending on our ends, norm-EI sees epistemic norms themselves as depending on our (epistemic) ends. I clarify these two points in turn.

According to source-EI, the reasons to be epistemically rational are what depends on our ends. Regardless of what epistemic norms require exactly, you have normative reason to conform to them because, and to the extent that doing so is a means to your ends. If you are in a situation where conforming to epistemic norms and being epistemically rational does not promote any of your ends, then you have no normative reason to be epistemically rational in that situation.

Norm-EI, in contrast, sees epistemic norms as conditional on our epistemic ends. And it does so in the sense that it takes those ends as among the conditions of application of epistemic norms. Recall that according to norm-EI, epistemic norms require, permit, or positively evaluate taking the means to one's epistemic ends. To be epistemically rational is to take the means to one's epistemic ends. As a result, having the relevant epistemic ends is part of the conditions under which you epistemically should take those means and form the relevant doxastic attitudes. If the epistemic end is not present, then the epistemic norm does not apply; it is not true, in other words, that you epistemically should e.g., follow the evidence. 
It ought to be clear that this last point is not about the normativity of epistemic norms. Rather, it is a point about the conditions under which it is true that, according to epistemic norms, you should have some doxastic attitude (whether or not you have any genuine normative reason to do what epistemic norms require or recommend). Compare this with a legal example. Suppose some law $\mathrm{L}$ requires all and only adults to do X. Being an adult is thus part of the conditions of application of L. If you are an adult, then it is true that, according to L, you should do $\mathrm{X}$. Unless you are an adult, it is not true that $L$ requires you to $X$. This, however, is not to say that $\mathrm{L}$ has genuine normative authority over you as soon as you are an adult. To say that $\mathrm{L}$ applies to you and that it requires you to do $\mathrm{X}$ is not to say that you have any normative reason to do what L "asks" you to do. In the same way, according to norm-EI, it is not true that you epistemically ought to do things like following the evidence unless you have the relevant epistemic ends. This, however, is not to say that such an epistemic norm has normative authority over you as soon as you have the relevant epistemic ends. To say that an epistemic norm applies to you and that it requires you to, e.g., follow the evidence, is not to say that you have any normative reason to do what that norm asks you to do. ${ }^{12} 13$

We are now in a position to see how each of norm-EI and source-EI, face their own version of the universality objection. Against source-EI, universalists will argue that there are cases where epistemic norms clearly have normative authority over you, even though conforming to them would not promote the satisfaction of any of your ends. In Delaware's beverage, the objection goes, epistemic norms seem authoritative for Nancy even though, plausibly, none of her ends would be promoted by believing the truth and avoiding error about Delaware's beverage. She still has genuine normative reasons, e.g., to not disbelieve Brett. Therefore, according to this version of the universality objection, the normative authority of epistemic norms cannot come from our ends.

Against norm-EI, in contrast, universalists will argue that there are cases where epistemic norms clearly require (or permit, or positively evaluate) having certain doxastic attitudes even though you lack the relevant epistemic end(s). Even if Nancy lacks the end of believing the truth and avoiding error about Delaware's beverage, believing what Brett tells her clearly counts as epistemically rational, good, justified, permissible and the like. Therefore, this other universality objection goes, having epistemic ends cannot be among the conditions of applications of epistemic norms.

Why does this matter? This has consequences, I will argue, for the strategies that instrumentalists have employed in response to the universality objection. Two of the most prominent and widely discussed strategies in defence of EI are only available to source-EI. These are the pragmatist strategy and the rule-based strategy. Even if those strategies were to

\footnotetext{
${ }^{12}$ Because, once again, you could claim that its normative authority comes from a source other than your ends. In that case, even if the instrumental epistemic norm would apply to you (because you are in the conditions under which these norms require things from people), that norm could still lack genuine authority. That is, it could still be the case that, even though the epistemic norm does "ask" you to believe something, you have no genuine reason to do as it says (just like you might have no genuine reason to respect a law that applies to you).

${ }^{13}$ For more on this distinction between norms merely issuing requirements or applying to us, and norms having genuine reason-giving authority over us, see e.g., Foot (1972), Broome (2013), and Côté-Bouchard (2016, 2017).
} 
succeed in the case of source-EI, instrumentalists who endorse norm-EI (either in addition to, or without source-EI) would still have to find other strategies to defend norm-EI against its own universality objection.

\subsubsection{The pragmatist strategy}

One common move in response to the universality objection is to distinguish between intellectualist and pragmatist forms of EI. ${ }^{14}$ For intellectualist EI, the ends that are relevant for epistemic norms are only distinctly epistemic or intellectual ends like the end of believing the truth and avoiding error. Pragmatist instrumentalists, in contrast, adopt a more liberal approach and take all our ends into account, not just epistemic ones. The hope is that by going pragmatist, instrumentalists will be able to invoke other ends that agents have in the alleged counterexamples. Even if agents in the examples lack epistemic ends, they still have other ends, and doing things like following the evidence might still promote the satisfaction of these other, nonepistemic ends. ${ }^{15}$

My goal here is not to assess the merits of this move. Rather, I will argue that the pragmatist strategy is only available to source-EI. Norm-EI cannot use it to deal with its own universality objection. Recall that for norm-EI, epistemic norms are a subset of instrumental norms; epistemic rationality is a subset of instrumental rationality. But what makes instrumental norms and instrumental rationality distinctly epistemic (and not, say, prudential) is that they require, permit or positively evaluate taking the means to one's distinctly epistemic ends (as opposed to non-epistemic ends like prudential ends). If you take the means to your practical ends, in contrast, then you are practically rational, not epistemically rational. As Richard Foley explains:

[I]f we are interested in identifying a distinctly epistemic kind of rationality, it is necessary to identify a distinctly epistemic goal. [...] I suggest that we take it to be [...] now to believe those propositions that are true and now not to believe those propositions that are false. [...] If a person has this goal and if on careful reflection he would believe $Y$ to be an effective means to this goal, then, all else being equal, it is rational (in an epistemic sense) for him to bring about Y. (Foley 1987, 7-8)

The problem is that the pragmatist strategy consists precisely in going beyond epistemic ends. And unlike source-EI, norm-EI cannot go beyond epistemic ends. What makes source-EI epistemic is not that it deals with epistemic ends, but rather that it is concerned with the authority of epistemic norms rather than, say, the authority of prudential norms. Once again, source-EI can remain agnostic about what these epistemic norms are like exactly. Proponents of source-EI are thus free to make use of non-epistemic ends in their answer to source-questions. They can claim that epistemic norms (regardless of what they require exactly) have authority because and insofar

\footnotetext{
${ }^{14}$ I borrow these labels from Lockard (2013).

${ }^{15}$ See e.g., Kornblith (1993) and Schroeder (2007, ch.6). Note, however, that Schroeder does not go as far as endorsing that pragmatist strategy. He only suggests it as a plausible possibility.
} 
as conforming to them promotes any of our ends, including non-epistemic ends like prudential or practical ends.

The same cannot be said of norm-EI. Norm-EI cannot go beyond epistemic ends without losing its identity as a form of epistemic instrumentalism. To illustrate this point, consider the following possible attempt at using the pragmatist strategy to defend norm-EI: even though the agent lacks the relevant epistemic ends in Kelly's examples, following the evidence still counts as instrumentally rational for them because doing so is still an excellent means to other, nonepistemic ends that they have. This, however, would be irrelevant to the universality objection as addressed to norm-EI. That objection is not that instrumentalists cannot view agents as instrumentally rational in the examples. Rather, it is that instrumentalists cannot view agents as epistemically rational in the examples. Universalists like Kelly could very well admit that instrumentalists can attribute some sort of instrumental rationality to those agents (like prudential rationality). But that would not undermine their point that agents in the counter-examples must also be seen as epistemically rational or irrational, and that norm-EI cannot deliver that result since (i) it claims that to be epistemically rational is to take the means to one's epistemic ends and (ii) the agents in the examples lack the relevant epistemic ends.

So, even if the pragmatist strategy is successful for source-EI, that would still not help norm-EI with its own universality objection. If the pragmatist move works, then conforming to epistemic norms is always a means to the satisfaction of at least some of our ends, including nonepistemic ends. But that would not rule out the possibility of situations where S's belief that $\mathrm{P}$ truly counts as epistemically rational or irrational even though S lacks the relevant epistemic end. Unlike source-EI, norm-EI can only be intellectualist. ${ }^{16}$

\subsubsection{The rule-based strategy}

One natural worry with the pragmatist strategy is that it cannot, in fact, vindicate the universality of epistemic normativity. After all, can't we also imagine cases where conforming to epistemic norms would not promote any of our ends? ${ }^{17}$ In part because of this, some instrumentalists have opted for a different kind of move in response to the universality objection. As Lockard (2013) explains, EI can be construed either in a case-based or rule-based way. This distinction can be seen as analogous to the one between act-utilitarianism and rule-utilitarianism in ethics:

According to this alternative [rule-based] picture, the instrumentalist is not claiming that it is rational for you to hold a belief in accordance with truth-conducive rules only if doing so on the particular occasion at hand would advance your ends. The idea is that the norms of epistemic rationality apply to your beliefs just in case compliance with them generally tends to advance your ends. Such a 'rule-based' form of epistemic pragmatism would be roughly analogous to rule utilitarianism, according to which the moral status of

\footnotetext{
${ }^{16}$ This is why radical pragmatists like Stich (1990) - who view doxastic attitudes as only subject to instrumental practical requirements - are not best seen as proponents of norm-EI.

${ }^{17}$ See e.g., Lockard (2013), Côté-Bouchard (2015), and Sharadin (2018).
} 
an act is determined by whether it was performed in compliance with rules that generally tend to maximize utility. (Lockard 2013, 1714)

Just like rule-utilitarianism does not require that each particular action maximizes utility on that particular occasion, rule-based EI does not require that each particular belief promotes the satisfaction of one's ends on that particular occasion. Instead, it says we should adopt a system of epistemic norms, the systematic following of which would promote the satisfaction of our ends over time.

So far, I have formulated the universality objection as an objection to case-based EI, i.e., to the claim that epistemic norms apply to you only if conforming to them would promote your ends in the particular case at hand. The counter-examples of authors like Kelly are typically examples where conforming to epistemic norms would not further their relevant ends in the particular case at hand. Given that, some instrumentalists have argued that taking the rule-based approach is the best way to avoid such counter-examples. ${ }^{18}$ The strategy is roughly this. Granted, there are cases where conforming to epistemic norms does not promote any of S's ends on that particular occasion. However, even in those exceptional situations, it remains true that systematically conforming to epistemic norms promotes S's ends in the long run. It remains true, in other words, that systematically following your evidence, for example, is the best policy for promoting the satisfaction of your ends over time. ${ }^{19}$

Once again, my aim is not to evaluate the merits of this move. Rather, it is to show that it is only available to source-EI. Norm-EI cannot use a rule-based strategy in response to its own universality objection. To see this, note first that rule-based EI is best seen as a form of sourceEI. For rule-based EI, the relevant means to our ends is the general policy of systematically following epistemic norms. This however, leaves open the question of what those epistemic norms are like exactly. In particular, it does not require that those epistemic norms be means-end requirements themselves. Norm-EI, in contrast, does not leave that question open. It does require that those epistemic norms be instrumental norms themselves. Norm-EI, in other words, just is an account of what we epistemically ought to do in particular cases: we epistemically ought to take the means to our epistemic ends. For rule-based EI, in contrast, what has to be instrumental are not the norms that it should be our general policy to follow. Instead, it is the justification for adopting that policy that is instrumental.

In fact, given the universality objection, it makes most sense for rule-based instrumentalists to reject norm-EI. The point of the rule-based strategy, in response to the universality objection, is precisely to avoid having to make epistemic norms dependent on our ends in each particular case. Its attraction is that it allows instrumentalists to say the following: although conforming to epistemic norms does not promote our ends in every particular case (as

\footnotetext{
${ }^{18}$ For instance Kornblith (1993) and Leite (2007).

${ }^{19}$ Note that this strategy is not mutually exclusive with the pragmatist strategy. Rule-based instrumentalists can be either pragmatist or intellectualist. That is, they can either focus on rules promoting our epistemic ends over time (e.g., Leite 2007) or promoting all of our ends over time (e.g., Kornblith 1993).
} 
the universality objection shows), conforming to epistemic norms in every particular case (even in particular cases where we lack epistemic ends) is the best means to our ends over time.

As with the pragmatist strategy, the success of the rule-based strategy would not help norm-EI with its own universality objection. Even if adopting the policy of systematically following epistemic norms turned out to best the best means to anyone's ends over time, that would not prevent universalist counter-examples to norm-EI specifically. That is, universalists could still come up with cases where S's belief that P counts as epistemically rational or irrational even though $\mathrm{S}$ lacks the relevant epistemic ends. It is not because adopting the general policy of conforming to epistemic norms promotes our ends that we always have epistemic ends in each particular case, which is what norm-EI needs. So, norm-EI cannot use the rule-based strategy either against its own universality objection.

To be clear, my point in this first subsection is not that the universality objection succeeds against norm-EI. Neither is it that norm-EI fares worse than source-EI against the objection. After all, I have not argued that the three strategies discussed above are the only ones available. Neither have I argued that those moves do, in fact, work for source-EI. For all I have said, there might be other moves, which norm-EI could successfully employ against its own universality objection. What I have argued is rather the three strategies discussed above are ones that norm-EI cannot use. Despite being relatively weak, this claim is by no means insignificant. For one thing, the three strategies in question are the most prominent and widely discussed ones in recent debates about EI. For another, it yields a significant conclusion: if instrumentalists want to defend norm-EI (either in addition to or without source-EI) against the universality objection, then the above replies won't do. They need to come up with some other reply, which will deal with norm-EI's own universality objection. This is a challenge that instrumentalists, for the most part, have not tried to meet. ${ }^{20}$

\subsection{Norm-EI, source-EI and the motivations for epistemic instrumentalism}

\subsubsection{Naturalism}

One of the most commonly invoked motivations for adopting EI is that it seems to provide a straightforward way to naturalize epistemology without abandoning its normative character. It is a well-known objection to the project of naturalizing epistemology - raised forcefully by Kim (1988) - that epistemological questions are autonomous from science because they are essentially normative. Just like scientific descriptions alone leave open the question of what we morally ought to do, they also leave open the question of what we ought to believe. However, an equally well-known reply - first due to Quine, and then picked up by numerous naturalists after him - is that epistemology is only normative in an instrumental sense. Normative

\footnotetext{
${ }^{20}$ One exception is Steglich-Petersen (2018). He argues that the universality objection fails because it assumes, wrongly, that epistemic norms must be understood in terms of doxastic obligations. If epistemic norms are permissions instead of obligations, the argument goes, then the universality objection loses its force. Unlike the moves discussed above, Steglich-Petersen's strategy does apply to norm-EI. Whatever the merits of this strategy (which there is no space to evaluate here), my point is that instrumentalists who want to defend norm-EI need to do like Steglich-Petersen and look for other moves in defense of norm-EI.
} 
epistemology is naturalizable, in other words, because epistemic instrumentalism is true, and instrumental normativity is naturalizable. As Quine puts it:

For me, normative epistemology is a branch of engineering. It is the technology of truthseeking, or, in more cautiously epistemic term, prediction. [...] There is no question here of ultimate value, as in morals; it is a matter of efficacy for an ulterior end, truth or prediction. The normative here, as elsewhere in engineering, becomes descriptive when the terminal parameter is expressed. (Quine 1998, 6645)

Since science can help us identify the best means to our given ends, it can tell us what we epistemically ought to believe. Following Wrenn (2006), I will refer to this as the engineering defence of epistemological naturalism. There is no space here to assess Kim's objection or the engineering reply here. What I would like to show, however, is that norm-EI is neither necessary nor sufficient for the engineering defence. More generally, naturalism has no interesting connection with norm-EI. It can only be a motivation to adopt source-EI.

Suppose naturalists only invoked norm-EI in response to Kim. That is, suppose they replied that epistemology can be naturalized because epistemic norms are requirements or permissions to take the means to our epistemic ends. For example, suppose they used SteglichPetersen's recent proposal and gave the following epistemic norm as an example:

"S ought to ensure that (if $\mathrm{S}$ believes that $\mathrm{p}$ with the aim of coming to a true belief as to whether $\mathrm{p}$, then $\mathrm{S}$ bases her belief as to whether $\mathrm{p}$ on adequate evidence)." (SteglichPetersen 2018, 274)

In response, nonnaturalists could simply ask the following. What about the 'ought' in this norm? Is it naturalizable? Is it a natural fact that we ought to ensure the coherence between our means and our end of believing the truth? Can science tell us that we ought to be instrumentally rational? The nonnaturalist objection is precisely that science alone cannot tell us what we ought to do. ${ }^{21}$

The point here is not that nonnaturalism is true and that there is nothing that a naturalist can respond. It is rather that there is nothing that norm-EI can respond without going beyond norm-EI. In order to respond to the line of nonnaturalist questioning just outlined, our naturalist will inevitably find herself giving an account of epistemic normativity. After all, as the nonnaturalist reply just sketched suggests, norm-EI is compatible with nonnaturalism. One can accept that epistemic norms are means-end requirements and also agree with the nonnaturalist that the 'ought' of epistemic instrumental rationality is not naturalizable. She could think, for instance, that it is a sui generis non-natural fact that we ought to take the means to our epistemic ends. Or perhaps taking the means to our epistemic ends is commanded by God. So, naturalists need more than norm-EI to naturalize epistemology.

\footnotetext{
${ }^{21}$ It is worth noting that Steglich-Petersen himself does not claim that this norm can be naturalized.
} 
Norm-EI is not necessary for the engineering reply either. One thing that a naturalist could respond to the above line of questioning is that the 'ought' in epistemic norms is natural because its normativity comes from our ends (i.e., because source-EI is true). That is, naturalists could (and many do) respond by explaining the normative authority of epistemic norms in terms of the naturalistic relation of promotion between means and ends. Source-EI can thus arguably help naturalists respond to Kim. Crucially, however, adding norm-EI to this response would not add anything that would help fending off the nonnaturalist critique.

Moreover, the real difficulty for naturalists, in response to people like Kim, is to give a naturalistic account of epistemic normativity. If source-EI is true, then naturalists might have that account regardless of what account of epistemic norms we then go for. If we managed to provide a sound naturalistic account of the normative authority of epistemic norms, Kim's worry would lose most of its force and there would be no need for naturalists to add norm-EI to the mix.

Norm-EI alone is thus irrelevant to the dispute between epistemological naturalists and nonnaturalists since it leaves open the question whether the normativity of epistemic norms can be understood naturalistically. ${ }^{22}$ Unlike source-EI, then, there is no interesting connection between norm-EI and naturalism.

\subsubsection{Practical utility}

Another prominent motivation for adopting EI is that conforming to epistemic norms tends to be tremendously useful for agents. Here is a common way to flesh out this idea. Typically, believing the truth about how to achieve an end allows you to achieve that end. Moreover, even when a true belief is not directly about how to achieve your ends, it could always be a premise in reasoning leading to true means-end beliefs. If this is right, then it seems that all true beliefs tend to have at least some practical utility. ${ }^{23}$ Even when they are not themselves useful truths about how to achieve your ends, they can potentially allow you, via reasoning, to get to other truths, which will themselves be useful truths about how to achieve your ends. ${ }^{24}$

This point is very much in the spirit of EI. If conforming to epistemic norms really is useful in that way, then it makes perfect sense to invoke that usefulness in accounting for epistemic normativity. If being epistemically rational is so useful, in other words, then it is clear why we should be epistemically rational. The reason is that it is useful; it tends to promote our ends. It is thus natural to think of the practical utility of epistemic norms as providing at least some motivation for EI.

\footnotetext{
22 See also Steglich-Petersen (2018, 261-262).

23 This is what Wrenn (2010) calls the "standard" argument for the instrumental value of true belief. It is also similar to the pragmatist strategies used by Kornblith (1993) and Schroeder (2007) in defence of source-EI.

${ }^{24}$ Although see Stich (1990) and Wrenn (2010) for doubts about this line of thought. Another common route to the usefulness of conforming to epistemic norms is via evolution and natural selection. As Quine puts it: "Creatures inveterately wrong in their inductions have a pathetic but praiseworthy tendency to die before reproducing their kind." (Quine 1969, 129)
} 
Some have sought to expand upon this motivation and to turn it into an argument for EI. One recent example is Christopher Cowie's (2014) "argument from coincidence."25 His argument takes the form of an explanatory challenge to EI's main rival, intrinsicalism, the view that epistemic normativity is a brute kind of normativity, not to be grounded in anything nonepistemic. The challenge is the following:

For intrinsicalists, practical utility can only be one of two sources [of epistemic normativity]. Intrinsicalists also think that it is a brutely epistemic normative truth [...] that evidence is normative for belief. [...] This is a very striking coincidence: there happens to be a brutely epistemic value in forming beliefs in a fashion that quite independently is already of great practical utility (and hence, value). [...] At the very least, it is a coincidence that calls out for an explanation from the intrinsicalist." (Cowie 2014, 4007-4008)

Cowie then goes on to argue that intrinsicalists cannot meet that explanatory challenge. Instrumentalists, in contrast, need not posit any such coincidence. For them, the practical utility of epistemic norms is all we need to explain their normativity.

My goal here is neither to evaluate Cowie's argument, nor the strength of practical utility as a motivation for EI. Instead, I would like to argue that just like naturalism, the practical utility of epistemic norms cannot be used as a motivation for norm-EI. It can only be a motivation for source-EI.

First, consider Cowie's argument. Cowie presents a challenge to intrinsicalism. Although it is clearly a rival to source-EI, intrinsicalism is not incompatible with norm-EI. Intrinsicalism and source-EI are answers to the source-questions and not to norm-questions. Just like norm-EI leaves open the question of the source of epistemic normativity, intrinsicalism leaves open the question of what epistemic norms are like exactly. As pointed out above, one could very claim that epistemic norms are requirements to take the means to our epistemic ends, while claiming that it as a brute fact that we should take those means.

Relatedly, Cowie's argument only concerns source-EI because it only arises in the context the question of why we have reason to conform to epistemic norms and be epistemically rational. Cowie's main point is that intrinsicalists are stuck with an implausible coincidence in their account of the source of epistemic normativity. EI, in contrast, posits no such coincidence. But this is only an advantage of source-EI because it is an advantage that it has as an account of the source of epistemic normativity. Since norm-EI is not an account of the source of epistemic normativity, it does not have that advantage.

So, norm-EI cannot use Cowie's argument. But can it at least invoke the practical utility of epistemic norms as a pro tanto motivation? It cannot, and this is for roughly the same reason that the pragmatist strategy against the universality objection is unavailable to norm-EI. It is because norm-EI cannot go beyond epistemic ends. It cannot be pragmatist. Someone is

${ }^{25}$ Other examples include Kornblith (1993) and Schroeder (2007). 
epistemically rational, according to norm-EI, when she takes the means to her epistemic ends. To take the means to one's practical ends is to be practically rational, not epistemically rational.

But the fact that things like believing the truth and following the evidence are practically useful has no bearing on whether epistemic norms requirements to take the means to our epistemic ends. The practical utility of conforming to epistemic norms leaves open the question of what these epistemic norms are like exactly. Specifically, it leaves open whether they are requirements to take the means to one's epistemic ends. Crucially, norm-EI could still be true if conforming to epistemic norms were not generally useful. And conforming to epistemic norms could still be extremely useful if norm-EI were false.

Granted, the practical utility of truth might show that it is useful to take the means to one's epistemic ends. But, once again, this has no bearing on the nature of epistemic rationality, i.e., on whether taking the means to epistemic ends is just what epistemic rationality and epistemic norms are about. It is no part of norm-EI that being epistemically rational is useful or practically rational. All that the practical utility of epistemic norms may show, given norm-EI, is that it is practically rational to be epistemically rational. But this is, at best, a consideration in favour of source-EI. It is of no help to norm-EI. So, just like naturalism, practical utility can only be a motivation to adopt source-EI.

As with the previous subsection, my point here is not that norm-EI is, in fact, unmotivated. Neither is it that source-EI is better motivated than norm-EI. This is because I have not argued that the two motivations discussed above are the only available ones. For all I have said, there might be other motivations, which norm-EI could invoke. My point is rather that the two motivations just discussed are ones that norm-EI cannot use. And once again, even though this claim is relatively weak, it still matters for the debate surrounding EI. For one thing, the two motivations just discussed are arguably the most prominent and widely discussed ones in recent debates about EI. For another, it yields a significant conclusion: if instrumentalists want to motivate norm-EI (either in addition to or without source-EI), then invoking naturalism or practical utility won't do. They need to come up with other considerations, which will motivate norm-EI specifically. This is a challenge that instrumentalists, for the most part, have not tried to meet. $^{26}$

\section{Conclusion: going forward}

I have done two main things in this paper. First, I have argued that there is an under-appreciated distinction between two types of epistemic instrumentalism (EI): instrumentalism about epistemic norms (norm-EI) and instrumentalism about the normativity of epistemic norms (source-EI). Norm-EI et and source-EI, I have argued, are not only distinct, but also independent. One does not entail the other. In part 2, I have argued that this distinction has significant consequences for the debate about EI. First, two of the most prominent instrumentalist strategies

\footnotetext{
${ }^{26}$ As before, Steglich-Petersen (2018) is an exception. One of the motivations he invokes is that EI would unify epistemic and practical normativity, thereby keeping things theoretically simpler than if the epistemic and the practical were distinct, isolated domains. This motivation is arguably relevant to both norm-EI and source-EI.
} 
in response to the well-known universality objection can only be used by source-EI. Norm-EI cannot use those moves in response to its own universality objection. Second, two of the most important considerations in favor of EI - naturalism and the practical utility of true beliefs - only favour source-EI.

I would like to end by raising two questions that instrumentalists should consider going forward. I have already anticipated the first one at the end of sections 2.1 and 2.2. It is a question to those who want to defend norm-EI, either in addition to, or without source-EI: why is norm-EI needed? Why should instrumentalists (or anyone) bother defending the claim that epistemic norms require, permit, or positively evaluate taking the means to our epistemic ends? After all, as we have seen, norm-EI cannot invoke two of the most prominent motivations for EI and it cannot use two of EI's most prominent strategies against the universality objection.

Second, the most prominent arguments that have been proposed for and against EI are really about source-EI. But given that, it is surprising that the following metanormative question has not received more attention from friends and foes of EI: can our ends really ground genuine normativity? ${ }^{27}$ Epistemic instrumentalists often write as if their view would be safe from serious criticism if they could show that conforming to epistemic norms always promotes the satisfaction of our ends. But this assumes a highly controversial metanormative claim, namely that our ends can be a source of genuine normativity in the first place; that merely having the end of $\varphi$-ing suffices to ground a pro tanto normative reason to $\varphi$. What underlies source-EI, in other words, is an instrumentalist account of normativity more generally: when there is normative reason for you to $\varphi$, it is ultimately in virtue of the fact that $\varphi$-ing is a means to the satisfaction of your ends in some sense. ${ }^{28}$ But this, again, is a highly controversial claim, independently of epistemic instrumentalism. ${ }^{29}$

So, going forward, source-instrumentalists should not only establish that conformity epistemic norms promotes ends-satisfaction whenever we think there are reasons to conform to epistemic norms. They should also tell us why we should accept their underlying metanormative commitment, namely that our ends can ground genuine normativity in the first place. Norminstrumentalists, on the other hand, should tell us why we should bother defending norm-EI, instead of just focusing on source-EI.

Acknowledgements Thanks to anonymous referees at Synthese for their helpful and generous feedback. I am also indebted to members of the Montréal Normativity Reading Group. Special thanks to Éliot Litalien, Marc-Kevin Daoust, Matthew Scarfone, and Tiger Zheng.

\section{References}

Alston, W. P. (1988). 'The deontological conception of epistemic justification.' Philosophical Perspectives, 2, 257-299.

\footnotetext{
${ }^{27}$ One exception is Schroeder (2007) whose sketch of source-EI is part of a larger case in favour of instrumentalism about all normativity and normative reasons.

${ }^{28}$ See e.g., Foot (1972), Williams (1979), Smith (1994), Schroeder (2007), and Goldman (2009) for versions of this view.

${ }^{29}$ See e.g., Hampton (1998), Cuneo (2007), Parfit (2011), Enoch (2011), and Scanlon (2014) for criticisms.
} 
Côté-Bouchard, C. (2015). 'Epistemic instrumentalism and the too few reasons objection.' International Journal of Philosophical Studies. 23 (3): 337-355.

Côté-Bouchard, C. (2016). 'Can the aim of belief ground epistemic normativity?' Philosophical Studies. 173: 3181-3198

Côté-Bouchard, C. (2017). 'Is epistemic normativity value-based?' Dialogue. 56, (3): 407-430

Broome, J. (2013). Rationality through reasoning. Chichester: Wiley

Cowie, C. (2014). 'In defence of instrumentalism about epistemic normativity.' Synthese 191 (16): 4003-4017.

Cuneo, T. (2007) The Normative Web, Oxford: Oxford University Press.

Enoch, D. (2011). Taking morality seriously: A defense of robust realism. Oxford University Press.

Fassio, D. (2015). 'The Aim of Belief.' the Internet Encyclopedia of Philosophy.

Feldman, R. (2000). 'The Ethics of Belief.' Philosophy and Phenomenological Research 60: 667-95.

Foley, R. (1987) The Theory of Epistemic Rationality, Cambridge, MA: Harvard University Press.

Foley, R. (1993) Working Without A Net, Oxford: Oxford University Press.

Foot, P. (1972) 'Morality as a System of Hypothetical Imperatives', Philosophical Review 81: 305-16.

Giere, R. N. (1989). 'Scientific rationality as instrumental rationality.' Studies in History and Philosophy of Science Part A 20 (3):377-384.

Goldman, A. H. (2009). Reasons From Within: Desires and Values. Oxford University Press.

Hampton, J. E. (1998) The authority of reason. Cambridge University Press, 1998.

Kelly, T. (2003) 'Epistemic Rationality as Instrumental Rationality: A Critique', Philosophy and Phenomenological Research 66(3): 612-40.

Kim, J. (1988) 'What is 'Naturalized Epistemology"?', in J.E. Tomberlin (ed.) Philosophical Perspectives: Volume 2, Atascadero, CA: Ridgeview, pp. 381-405.

Kornblith, H. (1993) 'Epistemic Normativity', Synthese 94: 357-76.

Laudan, L. (1990a) 'Normative Naturalism', Philosophy of Science 57: 44-59.

Laudan, L. (1990b) 'Aimless Epistemology?', Studies in History and Philosophy of Science 21: 315-22. 
Leite, A. (2007) 'Epistemic Instrumentalism and Reasons for Belief: A Reply to Tom Kelly's "Epistemic Rationality as Instrumental Rationality: A Critique"', Philosophy and Phenomenological Research 75(2): 456-64.

Littlejohn, C. (2012) Justification and the Truth-Connection, Cambridge: Cambridge University Press.

Lockard, M. (2013) 'Epistemic Instrumentalism', Synthese 190: 1701-18.

Maffie, J. (1990) 'Naturalism and the Normativity of Epistemology', Philosophical Studies 59: 333-49.

McHugh, C. (2012a). The Truth Norm of Belief. Pacific Philosophical Quarterly 93: 8-30.

McHugh, C. (2012b) 'Belief and Aims', Philosophical Studies 160(3): 425-39.

Millikan, R. G. (1984). Language, thought and other biological categories. Cambridge, MA: MIT Press.

Nelson, M. T. (2010). 'We Have No Positive Epistemic Duties.' Mind 119 (473): 83-102.

Nolfi, K. (2015). 'How to be a Normativist about the Nature of Belief.' Pacific Philosophical Quarterly, 96(2): 181-204.

Nozick, R. (1993). The nature of rationality. Princeton: Princeton University Press.

Papineau, D. (1999) 'Normativity and Judgment.' Aristotelian Society Supplementary Volume, Volume 73, Issue 1: 17-43.

Parfit, D. (2011) On What Matters, Oxford: Oxford University Press.

Quine, W.V.O. (1969) 'Natural Kinds', in Ontological Relativity and Other Essays, New York: Columbia UP.

Quine, W.V.O. (1998) 'Reply to Morton White', in L.E. Hahn and P.A. Schilpp (eds) The Philosophy of W.V. Quine, 2nd edn, Chicago, IL: Open Court.

Scanlon, T. M. (2014). Being realistic about reasons. Oxford University Press.

Schroeder, M. (2007) Slaves of the Passions, New York: Oxford University Press.

Shah, N., and J.D. Velleman (2005) 'Doxastic Deliberation', The Philosophical Review 114: 497-534.

Sharadin, N. (2018) 'Epistemic instrumentalism and the reason to believe in accord with the evidence', Synthese, 195 (9): 3791-3809.

Siegel, H. (1996). 'Instrumental rationality and naturalized philosophy of science.' Philosophy of Science 63 (3):124.

Smith, M. (1994) The Moral Problem, Oxford: Blackwell. 
Stapleford, S. (2015). 'Why There May Be Epistemic Duties.' Dialogue 54 (1):63-89.

Steglich-Petersen, A. (2006) 'No Norm Needed: On the Aim of Belief', The Philosophical Quarterly 56: 499-516.

Steglich-Petersen, A. (2009) 'Weighing the Aim of Belief', Philosophical Studies 145: 395-405.

Steglich-Petersen, A. (2018). 'Epistemic Instrumentalism, Permissibility, and Reasons for Belief' in Normativity: Epistemic and Practical, Eds Conor McHugh, Jonathan Way, and Daniel Whiting. Oxford University Press.

Stich, S. (1990) The Fragmentation of Reason, Cambridge, MA: MIT Press.

Velleman, J.D. (2000) 'On the Aim of Belief', in The Possibility of Practical Reason, Oxford: Oxford University Press.

Wedgwood, R. (2002) 'The Aim of Belief', Philosophical Perspectives 16: 267-97.

Whiting, D. (2013) 'Truth: The Aim and Norm of Belief', Teorema 32(3): 121-36.

Williams, B. (1973). 'Deciding to believe.' In Problems of the Self. Cambridge University Press.

Williams, B. (1979). 'Internal and External Reasons.' In Ross Harrison (ed.), Rational Action. Cambridge University Press.

Williamson, T. (2000). Knowledge and Its Limits. Oxford University Press.

Wrenn, C. (2006) 'Epistemology as Engineering?', Theoria 72(1): 60-79.

Wrenn, C. (2007). 'Why There Are No Epistemic Duties.' Dialogue 46 (1):115-1360.

Wrenn, C. (2010) 'True Belief is Not Instrumentally Valuable', in Cory D. Wright and Nikolaj J.L.L.Pedersen (eds) New Waves in Truth, New York, NY: Palgrave Macmillan. 